\title{
A study to investigate variations in biochemical and nutritional profile among severely wasted children on medical nutrition therapy: a hospital-based study
}

Varun Viswanathan ${ }^{1}$, Bina Dias ${ }^{2}$, Vishal D. Sawant ${ }^{3 *} \mathbb{C}$, Prachi Karnik ${ }^{1}$, Alka Jadhav ${ }^{4}$, Madhubala Jadhav ${ }^{1}$, Blossom Rodrigues ${ }^{5}$ and Lavina Fernandes ${ }^{5}$

\begin{abstract}
Aim and objectives: To study variations in biochemical and nutritional profile among children with severe thinness receiving medical nutrition therapy.

Methods: This study was conducted in 52 children of age between 5 and 12 years in Paediatric ward at Tertiary Care Centre over the period of 18 months. Serial anthropometry and blood collection was done on enrolment, 8 weeks and 6 months. Samples were analysed for serum lipid profile, calcium, magnesium, malondialdehyde and vitamin C levels.

Results: On enrolment all subjects had insufficient vitamin C levels, increased malondialdehyde levels, micronutrient deficiencies and altered lipid profile with less than desirable cholesterol, borderline HDL, severely low LDL and acceptable triglyceride levels. Subjects were started on MNT, i.e. indigenously prepared Ready-to-use therapeutic food. At 8 weeks, MNT improved vitamin C levels (91.1\%) and 80\% subjects had normalised malondialdehyde values and improvement in micronutrients with cholesterol (desirable in 44.4\%), HDL (desirable in 51.1\%), LDL values (acceptable in 24.4\%) and triglyceride (high in 20.5\%). At 6 months, subjects maintained vitamin C values to sufficient (81.5\%) with normalising of MDA in $81.8 \%$ of subjects and with cholesterol (desirable in 55\%), HDL (desirable in 33.1\%) LDL (acceptable in 22.1\%), and triglyceride (acceptable in 60\%) and maintaining of micronutrients within normal ranges. $33.33 \%$ subjects showed improvement to thinness at the end of 6 months, while $44 \%$ subjects became normal by the end of study.
\end{abstract}

Conclusion: MNT or Ready-to-use therapeutic food (RUTF) is effective in treating acute malnutrition and promoted as the treatment of choice for children in age group of 5-12 years.

Keywords: Malnutrition, Medical nutrition therapy, Biochemical profile, Vitamin C, Malondialdehyde

\footnotetext{
*Correspondence: vsawant1989@ymail.com

${ }^{3}$ Department of Paediatrics, TNMC \& BYL Nair Hospital, Mumbai,

Maharashtra 400008, India
}

Full list of author information is available at the end of the article

\section{Background}

The term malnutrition includes overnutrition and undernutrition, referring to multiple conditions including acute and chronic malnutrition and micronutrient deficiencies. Chronic malnutrition results from insufficient intake or absorption of essential nutrients over a period of time. Micronutrient deficiencies are a form of chronic malnutrition that can have various impacts on health, 
development, and productivity. Because visible signs are not always present, they are often referred to as hidden hunger (Lenters et al. 2016). Severe acute malnutrition (SAM) was divided into non-oedematous severe acute malnutrition and oedematous malnutrition previously characterised as marasmus and kwashiorkor, respectively.

Free radicals include reactive oxygen species like hydroxyl, superoxide ions which are produced during metabolic reactions. The concentration of free radicals in excess leads to generation of oxidative stress which when coupled with deficiency of anti-oxidants like vitamin C, E contributes to tissue damage and generation of by-products like malondialdehyde. This accelerates apoptosis and may contribute to severe acute malnutrition (Catal et al. 2007). This theory gives a new perspective and may offer insights in the management of severe thinness and severe acute malnutrition.

Severe acute malnutrition is due to deficiency of type II nutrients which leads to growth failure. It is most likely due to decreased food intake but disease can also exacerbate severe acute malnutrition. The disease worsens SAM by reducing appetite and in turn SAM suppresses immune function leading to a vicious and never-ending cycle. In extreme scenarios, SAM leads to the syndromes known as marasmus and kwashiorkor. The older hypothesis was that marasmus is the extreme result of adaptation to low intake, with complete growth retardation and severe loss of muscle and adipose tissue, while kwashiorkor characterised by oedema and fatty liver may represent a failure in some aspect of this adaptation (Emery 2005).

SAM leads to dyslipidaemia due to increased levels of cortisol and growth hormone with reduced levels of insulin-like growth factor (Sawaya et al. 2009; Veiga et al. 2010). Studies on lipid profile in malnourished children are very scarce. The present hospital-based study was conducted to investigate variations in biochemical profile among children on medical nutrition therapy.

\section{Methods}

This prospective observational hospital-based study was conducted among 52 children of age 5-12 years in Paediatric ward at a Tertiary Care Centre and Urban Health Centre attached to Tertiary Care Centre over the period of 18 months. The study was started after institutional ethics committee clearance was obtained (ref no D0201743). A patient information sheet was given to the subject's parent/guardian that had explained the study details. Written informed consent was obtained from the parents. Demographic details and chief complaints like fever, weight loss, cough, diarrhoea, any other were noted in predesigned proforma. Past history of tuberculosis/ contact was enquired.
A complete history and clinical examination was noted. Anthropometric measurements were taken of admitted children, i.e. weight and height. Body mass index (BMI) was calculated, and children were classified as thinness and severe thinness as per WHO standard growth charts 2007. The detailed anthropometry was done as (1) the weight was taken using standard electronic weighing scale with the accuracy up to 10 g. (2) Height was taken using a stadiometer with the accuracy of $1 \mathrm{~mm}$; (3) body mass index was calculated using formula: weight in $\mathrm{kg} /$ (height in $\mathrm{m}^{2}$ ). Malnutrition was classified according to the WHO guidelines taking only BMI parameter between 5 and 12 years. (1) BMI less than -3 SD were designated as severe thinness; (2) those falling below -2 SD and more than or equal to -3SD were designated as thinness. Subjects falling in severe thinness were considered as potential study population. All children underwent the appetite test (https://motherchildnutrition.org/resources/pdf/ mon-ethiopia-sam-guidelines.pdf). They were given the amount of Medical Nutrition Therapy (MNT) to be eaten in one seating as per appetite test chart (https:// motherchildnutrition.org/resources/pdf/mcn-ethiopiasam-guidelines.pdf). If they consume the minimum necessary amount of MNT, they were considered as pass.

Subjects already on vitamin/mineral or any other nutritional supplementation, who failed appetite test, subjects with complication, immune compromised state, tuberculosis and any other chronic illness were excluded from the study. All Severely Thin (ST) subjects were enrolled in the study on passing the appetite test and started on MNT for 8 weeks along with good feeding practice. MNT was given daily for 8 weeks according to MNT delivery chart (https://motherchildnutrition.org/resou rces/pdf/mcn-ethiopia-sam-guidelines.pdf; Sawant et al. 2021). Parents were counselled on good hygiene practices and switched to a home-based diet following 8 weeks. MNT or Ready-to-Use Therapeutic Food (RUTF) is also an energy-dense, fortified micronutrient paste commonly used for therapeutic feeding in children with SAM. Their effects in ST children are not studied widely. MNT was prepared indigenously in our production unit according to WHO standards for RUTF composition (Sawant et al. 2021; Jadhav et al. 2019). Steps involved are fine mixing of powdered sugar (28\%), skimmed milk powder (24\%), soybean oil (21\%), Aflatoxin tested peanut butter (25\%), emulsifier and micronutrients (2\%) as per WHO specifications. They were grinded to achieve a particle size of up to 300 micron and packaging with nitrogen flush (Sawant et al. 2021; Jadhav et al. 2019). One sachet of $92 \mathrm{~g}$ provides $500 \mathrm{kcal}$ and $14.6 \mathrm{gm}$ of proteins. Composition of MNT is given in Tables 1 and 2 . 
Table 1 Composition of medical nutrition therapy MNT (RUTF) (Jadhav et al. 2016)

\begin{tabular}{ll}
\hline Ingredients & \% Weight \\
\hline Peanut paste & 25 \\
Skimmed milk powder & 24 \\
Powdered sugar & 28 \\
Soyabean oil & 20.8 \\
Micronutrient mix & 1.6 \\
Emulsifiers & 0.6 \\
\hline
\end{tabular}

Table 2 Nutrient composition of Medical Nutrition Therapy (MNT) as per WHO recommendation (Jadhav et al. 2016)

\begin{tabular}{ll}
\hline Nutrientper100gmofMNT & \\
\hline Energy & $560 \mathrm{kcal}$ \\
Protein & $14.6 \mathrm{~g}$ \\
Carbohydrate & $49 \mathrm{~g}$ \\
Fat & $34.5 \mathrm{~g}$ \\
Sodium & $135 \mathrm{mg}$ \\
Potassium & $1220 \mathrm{mg}$ \\
Calcium & $578 \mathrm{mg}$ \\
Phosphorous & $288 \mathrm{mg}$ \\
Magnesium & $85 \mathrm{mg}$ \\
Iron & $12 \mathrm{mg}$ \\
Zinc & $12 \mathrm{mg}$ \\
Copper & $1.5 \mathrm{mg}$ \\
Selenium & $20 \mathrm{mcg}$ \\
lodine & $80 \mathrm{mcg}$ \\
Vitamin A & $1.1 \mathrm{mg}$ \\
Vitamin D & $17.1 \mathrm{mcg}$ \\
Vitamin E & $20.6 \mathrm{mg}$ \\
Vitamin K & $21 \mathrm{mcg}$ \\
Vitamin B1 & $0.6 \mathrm{mg}$ \\
Vitamin B2 & $1.9 \mathrm{mg}$ \\
Vitamin C & $53 \mathrm{mg}$ \\
Vitamin B6 & $0.6 \mathrm{mg}$ \\
Vitamin B12 & $1.76 \mathrm{mcg}$ \\
Vitamin B9 & $210 \mathrm{mcg}$ \\
Vitamin B3 & $5.31 \mathrm{mg}$ \\
Vitamin B5 & $3.1 \mathrm{mg}$ \\
Vitamin B7 & $66 \mathrm{mcg}$ \\
\hline & \\
\hline &
\end{tabular}

Blood collection of the subjects was done at enrolment, i.e. Pre-MNT, at 8 weeks of completion of therapy and at the end of 6 months from the date of enrolment. Anthropometric data were recorded at every visit. Anthropometric and biochemical data was analysed at 2 time points at 8 weeks and 6 months. Samples were analysed for changes in serum lipid profile, serum magnesium and calcium representing the micronutrients and malondialdehyde level that increases during oxidative stress and vitamin $C$ levels depicting the antioxidant status. Vitamin $C$ levels are estimated by Harris and Ray method invented in 1935. Serum Malondialdehyde (MDA) levels are estimated by modified Sadasivudu et al. invented in 1999. Serum triglyceride Estimation was done using colorimetric enzymatic test using glycerol-3-phosphateoxidase (GPO). Cholesterol Estimation was done using enzymatic method. High-Density Lipoprotein (HDL) Estimation was done using Direct Enzymatic colorimetric. Low-Density Lipoprotein (LDL) Estimation was calculated by Friedewald's Formula. Serum Calcium Estimation was done Arsenazo III. Serum Magnesium Estimation was done using Agappe 120FR Syre reagent.

\section{Statistical analysis}

Sample size of the study was determined using SAS 9.2 package. Minimum sample size of 43 will have $80 \%$ power to detect change of mean 5 and SD 3.5 at alpha $=0.05$. All the data were analysed using SPSS V 15.0 (Statistical Package for Social Sciences, Version 15.0). Data were given as mean and SD for quantitative variables and number (percentage \%) for qualitative variables. Student's paired $t$ tests were used to compare pre- and postvalues for continuous data. All tests were 2 tailed. Level of Significance was taken as $P \leq 0.05$. $\mathrm{S}=$ significant, $\mathrm{NS}=$ not significant, $\mathrm{P}=$ probability value, $\mathrm{DF}=$ degrees of freedom.

\section{Results}

A total of 52 subjects were enrolled in the study. Among them $50 \%$ were boys and $50 \%$ were girls with Male: Female Ratio being 1:1. Predominant age group for boys was 7 years $(26.9 \%)$ and for girls was 6 years $(23.1 \%)$ as depicted in Table 3. Subjects presented mainly with weight loss (46.2\%) and fever (25\%). On follow-up, at 8 weeks, we had 45 subjects and at 6 months only 27 subjects, respectively.

Table 3 Age and sex distribution on enrolment

\begin{tabular}{lccr}
\hline Age (in years) & Boys (\%) & Girls (\%) & \multicolumn{1}{c}{ Total } \\
\hline $5-6$ & $4(15.4 \%)$ & $4(15.4 \%)$ & $8(15.4 \%)$ \\
$6-7$ & $3(11.5 \%)$ & $6(23.1 \%)$ & $9(17.3 \%)$ \\
$7-8$ & $7(26.9 \%)$ & $4(15.4 \%)$ & $11(21.2 \%)$ \\
$8-9$ & $6(23.1 \%)$ & $2(7.7 \%)$ & $8(15.4 \%)$ \\
$9-10$ & $5(19.2 \%)$ & $3(11.5 \%)$ & $8(15.4 \%)$ \\
$10-11$ & $0(0 \%)$ & $3(11.5 \%)$ & $3(5.8 \%)$ \\
$11-12$ & $1(3.8 \%)$ & $4(15.4 \%)$ & $5(9.6 \%)$ \\
Total & $26(100 \%)$ & $26(100 \%)$ & $52(100 \%)$ \\
\hline
\end{tabular}


Mean weight, mean height, mean BMI on enrolment for all subjects were $15.85 \pm 4.08 \mathrm{~kg}, 114.33 \pm 14.06 \mathrm{~cm}$ \& $11.92 \pm 0.44 \mathrm{~kg} / \mathrm{m}^{2}$, respectively. At 8 weeks, mean weight, mean height and BMI were $17.35 \pm 4.55 \mathrm{~kg}$, $115.27 \pm 14.06 \mathrm{~cm}$ and $12.89 \pm 0.67 \mathrm{~kg} / \mathrm{m}^{2}$ respectively which were statistically significant. Baseline and follow-up characteristics of nutritional profile are given in Table 4 .

At 6 months, mean weight, mean height and mean BMI were $19.33 \pm 5.12 \mathrm{~kg}, 120.21 \pm 15.29 \mathrm{~cm}$ and $13.26 \pm 0.96 \mathrm{~kg} / \mathrm{m}^{2}$, respectively. The rate of weight gain was calculated as grams of weight gain per kilogram body weight/day. From enrolment to 8 weeks, it was $1.67 \mathrm{~g} / \mathrm{kg} /$ day and from 8 weeks to 6 months, it was $0.36 \mathrm{gm} / \mathrm{kg} /$ day ( $P$ value of $<0.001$ ), while overall rate of weight gain from enrolment to 6 months was $0.84 \mathrm{gm} / \mathrm{kg} /$ day.

On assessment of nutritional status, $73.33 \%$ subjects became thin and $17.8 \%$ became normal and $8.8 \%$ continued to remain severely thin at the 8 weeks of MNT treatment and at the end of 6 months 33.33\% became Thin, $44.4 \%$ became normal and $22.22 \%$ continued to remain Severe Thin. None of the children became overweight or obese.

On enrolment all subjects had insufficient vitamin $C$ levels, increased MDA levels, micronutrient deficiencies and altered lipid profile with less than desirable (Daniels and Greer 2008; McNeal et al. 2013) cholesterol, borderline HDL, severely low LDL and acceptable triglyceride levels (Daniels and Greer 2008; McNeal et al. 2013).

At 8-week follow-up, there was a sharp decline in serum MDA levels from 5.77 to 3.64 micromoles/l followed by 3.49 micromoles/1 at 6-month follow-up. On an average serum MDA levels were maintained between 3.6 and $4 \mathrm{mmol} / \mathrm{l}(29.6 \%)$ at 6 months. At enrolment high MDA levels were observed suggestive of increased oxidative stress while at 8 weeks there was a dramatic decline in serum MDA levels suggestive of redox reaction. At 6 months, normalisation of malondialdehyde continued in about $81.8 \%$ subjects.
At 8 weeks, vitamin C levels improved from $0.46 \mathrm{mg} / \mathrm{lit}$ to sufficient levels of $0.69 \mathrm{mg} / \mathrm{lit}$ in $91.1 \%$ subjects and on 6-month follow-up it was $0.73 \mathrm{mg} / \mathrm{lit}$ in $81.5 \%$ subjects.

MNT is lipid-rich. There is a concern of dyslipidemia in preadolescent age group. Hence we studied the changes in Lipid profile in these Severe Thin children.

The mean total cholesterol was $121.93 \mathrm{mg} / \mathrm{dl}$ on enrolment, which improved to $148.29 \mathrm{mg} / \mathrm{dl}$ at 8 weeks, and $150.96 \mathrm{mg} / \mathrm{dl}$ at 6 months. On enrolment $92.3 \%$ subjects had total cholesterol below desirable (Daniels and Greer 2008; McNeal et al. 2013) levels with Only $1.9 \%$ of the children having borderline high serum cholesterol. At 8 weeks the cholesterol improved to desirable in $44.4 \%$ pts while $8.9 \%$ subjects reached borderline high values. On follow-up at 6 months, subjects maintained desirable levels of cholesterol, (55.6\%). Borderline high (Daniels and Greer 2008; McNeal et al. 2013) cholesterol levels dropped from 8.9 to $3.7 \%$ at end of 6 months. None of the candidates had high cholesterol levels at any point of time.

About HDL Cholesterol, mean HDL cholesterol was $41.73 \mathrm{mg} / \mathrm{dl}$ on enrolment which improved to $52.56 \mathrm{mg} /$ $\mathrm{dl}$ at 8 weeks and $55.30 \mathrm{mg} / \mathrm{dl}$ at 6 months. On enrolment $11.5 \%$ of the subjects had low and $57.7 \%$ had borderline low HDL cholesterol levels. At 8-week follow-up, HDL improved to desirable in $51.1 \%$ and borderline high in $31.1 \%$ subjects. This can be attributed to soya oil of MNT. At end of 6 months, HDL values returned almost to a Pre-MNT level, i.e. $11.1 \%$ had low HDL and 55.6\% had borderline low HDL values.

On enrolment, mean LDL cholesterol was $63.16 \mathrm{mg} / \mathrm{dl}$ on enrolment which improved to $75.36 \mathrm{mg} / \mathrm{dl}$ at 8 weeks and $78.56 \mathrm{mg} / \mathrm{dl}$ at 6 months. LDL values were severely low in $76.9 \%$ and acceptable in $5.8 \%$ of subjects. At 8 weeks, LDL levels rose to borderline low (42.2\%). and acceptable levels (24.4\%) in subjects. At 6 months, LDL levels were maintained to borderline low (44.4\%) and acceptable levels $(22.2 \%)$ in subjects. None of our study subjects had borderline high or undesirable (Daniels and

Table 4 Baseline and follow-up characteristics

\begin{tabular}{|c|c|c|c|}
\hline Parameter (A) & On enrolment $(N=52)$ & 8 weeks follow-up $(N=45)$ & $\begin{array}{l}6 \text { months follow-up } \\
(N=27)\end{array}$ \\
\hline Weight (kg) & 15.85 kg & $17.35 \mathrm{~kg}$ & $19.33 \mathrm{~kg}$ \\
\hline Height (cm) & $114.33 \mathrm{~cm}$ & $115.27 \mathrm{~cm}$ & $120.21 \mathrm{~cm}$ \\
\hline BMI (kg/m2) & $11.92 \mathrm{~kg} / \mathrm{m} 2$ & $12.89 \mathrm{~kg} / \mathrm{m}^{2}$ & $13.26 \mathrm{~kg} / \mathrm{m}^{2}$ \\
\hline Parameter (B) & Enrolment to 8 weeks & 8 weeks to 6 months & Enrolment to 6 months \\
\hline Mean weight gain $(\mathrm{Kg})$ & $1.5 \mathrm{~kg}$ & $1.98 \mathrm{~kg}$ & $3.48 \mathrm{~kg}$ \\
\hline Rate of weight gain (gms/kg/day) & $1.67 \mathrm{gms} / \mathrm{kg} /$ day & $0.36 \mathrm{gms} / \mathrm{kg} /$ day & $0.84 \mathrm{gms} / \mathrm{kg} /$ day \\
\hline Change in BMI & $0.97 \mathrm{~kg} / \mathrm{m}^{2}$ & $0.37 \mathrm{~kg} / \mathrm{m}^{2}$ & $1.34 \mathrm{~kg} / \mathrm{m}^{2}$ \\
\hline
\end{tabular}


Greer 2008; McNeal et al. 2013) LDL levels on enrolment as well as at 8 weeks and 6 months.

Triglyceride values were split into age groups of 5-9 years and 10-12 years for interpretation as per reference range of American Association of Paediatrics (Daniels and Greer 2008; McNeal et al. 2013). It was observed that in the age group of 5-9 years, the mean triglyceride was $72.23 \mathrm{mg} / \mathrm{dl}$ on enrolment which improved to $118.26 \mathrm{mg} /$ $\mathrm{dl}$ at 8 weeks and $120.91 \mathrm{mg} / \mathrm{dl}$ at 6 months. On enrolment only $50 \%$ of subjects had acceptable triglyceride levels, 38.6\% had borderline high, 9.1\% had high and 2.3\% had severely high serum triglyceride levels. At 8 weeks triglyceride levels were normal in $22.4 \%$, borderline high in $51.3 \%$, high in $20.5 \%$ and severely high in $5.5 \%$. And at 6-month follow-up $63.6 \%$ had normal levels, $36.4 \%$ had borderline high triglycerides and none had high or severely high values $(p<0.001)$.

In the age group of 10-12 years, mean triglyceride was $93.33 \mathrm{mg} / \mathrm{dl}$ on enrolment which improved to $115.83 \mathrm{mg} /$ $\mathrm{dl}$ at 8 weeks and $120.91 \mathrm{mg} / \mathrm{dl}$ at 6 months. On enrolment only $50 \%$ of subjects had acceptable triglyceride levels, $37.5 \%$ had borderline high, $12.5 \%$ had high levels. At 8 weeks triglyceride levels were normal in $34.6 \%$, borderline high in $66.4 \%$, and none had high or severely high levels. And at 6-month follow-up 60\% had normal levels, $20 \%$ had borderline high and $20 \%$ had high triglyceride values.

The mean serum calcium levels were $8.62 \mathrm{mg} / \mathrm{dl}$ on enrolment which improved to $9.47 \mathrm{mg} / \mathrm{dl}$ at 8 weeks and $9.29 \mathrm{mg} / \mathrm{dl}$ at 6 months. Serum calcium levels were low $(8.0-8.4 \mathrm{mg} / \mathrm{dl})$ in $30.8 \%$ of the subjects on enrolment which improved to $4.5 \%$ having low Calcium levels at 8 weeks and $11.1 \%$ having low levels at 6 -month follow-up.

Nobody had low serum magnesium levels at any time. The mean serum magnesium levels were $1.67 \mathrm{mg} / \mathrm{dl}$ on enrolment which improved to 2.10 at 8 weeks and 2.04 at 6 months. Serum magnesium levels were found to be borderline low, i.e. between 1.5 and $1.7 \mathrm{mg} / \mathrm{dl}$ in $61.5 \%$ of subjects on enrolment which became $6.7 \%$ at 8 weeks and $3.7 \%$ at 6 months $(p<0.001)$.

Mean values of all biochemical parameters on enrolment, 8 weeks and 6 months are shown in Table 5 .

The comparison of biochemical parameters at enrolment, 8 weeks, 6 months is shown in Table 6 .

\section{Discussion}

The present study was carried out with the objective of studying the biochemical impact of medical nutrition therapy, i.e. indigenously prepared Ready-to-use Therapeutic food in children with severe thinness. The subjects had their biochemical parameters evaluated on enrolments, at 8 weeks and 6 months. 45 subjects out of 52 followed up to 8 weeks while 7 subjects were lost to follow-up. We do not know about the mortality of these 7 subjects. 27 out of 45 subjects followed up to 6 months while 18 subjects were lost to follow-up.

On enrolment, 100\% subjects had elevated serum MDA levels suggestive of oxidative injury with mean of $5.77 \pm 0.35$ micromoles/l. At 8 weeks, $80 \%$ subjects had declining serum MDA levels with mean of $3.64 \pm 0.55$ micromoles/l with $\mathrm{t}$ value of 20 and $p$ value $<0.001$ which was statistically significant. The improvement in serum MDA level was probably due to rich anti-oxidant content of MNT which counteracts free radical damage and reduces oxidative injury. On follow-up at 6 months, it was observed that serum MDA levels continued to be declining with mean of $3.49 \pm 0.53$ micromoles/ 1 with $\mathrm{t}$ value of 1.9 and $\mathrm{p}$ value of less than 0.07 which was statistically insignificant. These findings are correlated well with the study done by Ghone et al. (2013) and Jain et al. (2008). Overall there was normalisation of serum malondialdehyde levels from a mean of $5.77 \pm 0.35$ $3.49 \pm 0.53$ micromoles/ 1 with a $\mathrm{t}$ value of 16.6 with a $p$ value of less than 0.001 which was statistically significant.

Table 5 Mean values of all biochemical parameters on enrolment, 8 weeks and 6 months

\begin{tabular}{lccc}
\hline Parameter & On enrolment & $\mathbf{8}$ weeks follow-up & $\mathbf{6}$ months follow-up \\
\hline Sr. Malondialdehyde (micromoles/litre) & $5.77 \pm 0.35$ & $3.64 \pm 0.55$ & $3.49 \pm 0.53$ \\
Vitamin C (mg/l) & $0.46 \pm 0.05$ & $0.69 \pm 0.10$ & $0.73 \pm 0.10$ \\
Cholesterol (mg/dl) & $121.93 \pm 20.96$ & $148.29 \pm 16.96$ & $150.96 \pm 14.47$ \\
HDL $(\mathrm{mg} / \mathrm{dl})$ & $41.73 \pm 6.54$ & $52.56 \pm 7.15$ & $55.30 \pm 6.63$ \\
LDL $(\mathrm{mg} / \mathrm{dl})$ & $63.16 \pm 16.13$ & $75.36 \pm 11.88$ & $78.56 \pm 10.75$ \\
Triglycerides (mg/dl)(5-9 years) & $72.23 \pm 18.04$ & $118.26 \pm 27.37$ & $120.91 \pm 14.89$ \\
Triglycerides (mg/dl) (10-12 years) & $93.33 \pm 25.46$ & $115.83 \pm 21.35$ & $120.91 \pm 14.89$ \\
Calcium (mg/dl) & $8.62 \pm 0.45$ & $9.47 \pm 0.57$ & $9.29 \pm 0.27$ \\
Magnesium (mg/dl) & $1.67 \pm 0.24$ & $2.10 \pm 0.28$ & $2.04 \pm 0.18$ \\
\hline
\end{tabular}


Table 6 Comparison of biochemical parameters at enrolment, 8 weeks, 6 months

\begin{tabular}{|c|c|c|c|}
\hline & Enrolment $(n=52)$ & 8 weeks $(n=45)$ & 6 Months $(n=27)$ \\
\hline \multicolumn{4}{|l|}{ Biochemical parameters } \\
\hline \multicolumn{4}{|c|}{ Serum Malondialdehyde (micromole/l) } \\
\hline$\leq 3.0$ & $0(0 \%)$ & $6(13.3 \%)$ & $7(25.9 \%)$ \\
\hline $3.1-3.5$ & $0(0 \%)$ & $13(28.9 \%)$ & $7(25.9 \%)$ \\
\hline $3.6-4.0$ & $0(0 \%)$ & $17(37.8 \%)$ & $8(29.6 \%)$ \\
\hline $4.1-4.5$ & $0(0 \%)$ & $8(17.8 \%)$ & $5(18.5 \%)$ \\
\hline $4.6-5.0$ & $1(1.9 \%)$ & $0(0 \%)$ & $0(0 \%)$ \\
\hline $5.1-5.5$ & $15(28.9 \%)$ & $0(0 \%)$ & $0(0 \%)$ \\
\hline $5.6-6.0$ & $22(42.3 \%)$ & $1(2.2 \%)$ & $0(0 \%)$ \\
\hline$>6.0$ & $14(26.9 \%)$ & $0(0 \%)$ & $0(0 \%)$ \\
\hline \multicolumn{4}{|l|}{ Vitamin C (mg/dl) } \\
\hline$<0.30$ (deficiency) & $0(0 \%)$ & $0(0 \%)$ & $0(0 \%)$ \\
\hline 0.4-0.6 (insufficiency) & $52(100 \%)$ & $4(8.9 \%)$ & $5(18.5 \%)$ \\
\hline$>0.6$ (sufficiency) & $0(0 \%)$ & $41(91.1 \%)$ & $22(81.5 \%)$ \\
\hline \multicolumn{4}{|c|}{ Serum cholesterol (mg/dl) (Daniels and Greer 2008; McNeal et al. 2013) } \\
\hline $\operatorname{Low}(<125)$ & $29(55.8 \%)$ & $4(8.9 \%)$ & $1(3.7 \%)$ \\
\hline Borderline Low(126-150) & 19(36.5\%) & $17(37.8 \%)$ & 10(37\%) \\
\hline Desirable (151-170) & $3(5.8 \%)$ & $20(44.4 \%)$ & $15(55.6 \%)$ \\
\hline Borderline(170-199) & $1(1.9 \%)$ & $4(8.9 \%)$ & $1(3.7 \%)$ \\
\hline High (>200) & $0(0 \%)$ & $0(0 \%)$ & $0(0 \%)$ \\
\hline \multicolumn{4}{|c|}{ High-density lipoprotein (HDL) (35-80 mg/dl) (Daniels and Greer 2008; McNeal et al. 2013) } \\
\hline Undesirable $(<35)$ & $6(11.5 \%)$ & $0(0 \%)$ & $3(11.1 \%)$ \\
\hline Borderline (35-45) & $30(57.7 \%)$ & $8(17.8 \%)$ & $15(55.6 \%)$ \\
\hline Desirable (46-55) & $16(30.8 \%)$ & $23(51.1 \%)$ & 9(33.3\%) \\
\hline Borderline high (56-70) & $0(0 \%)$ & 14(31.1\%) & $0(0 \%)$ \\
\hline Elevated $(>70)$ & $0(0 \%)$ & $0(0 \%)$ & $0(0 \%)$ \\
\hline \multicolumn{4}{|c|}{ Low-density lipoprotein (LDL) (mg/dl) (Daniels and Greer 2008; McNeal et al. 2013) } \\
\hline Severely low (51-75) & $40(76.9 \%)$ & 15(33.3\%) & $9(33.3 \%)$ \\
\hline Borderline low (76-89) & $9(17.3 \%)$ & $19(42.2 \%)$ & $12(44.4 \%)$ \\
\hline Acceptable (90-110) & $3(5.8 \%)$ & $11(24.4 \%)$ & $6(22.2 \%)$ \\
\hline Borderline (111-129) & $0(0 \%)$ & $0(0 \%)$ & $0(0 \%)$ \\
\hline Undesirable ( $\geq 130)$ & $0(0 \%)$ & $0(0 \%)$ & $0(0 \%)$ \\
\hline \multicolumn{4}{|c|}{ Triglycerides (mg/dl) 5-9 years (Daniels and Greer 2008; McNeal et al. 2013) } \\
\hline Acceptable (50-75) & $22(50 \%)$ & $9(23.1 \%)$ & $14(63.6 \%)$ \\
\hline Borderline(76-99) & $17(38.6 \%)$ & $20(51.3 \%)$ & $8(36.4 \%)$ \\
\hline High (100-125) & $4(9.1 \%)$ & $8(20.5 \%)$ & $0(0 \%)$ \\
\hline Severely high ( $\geq 125$ ) & $1(2.3 \%)$ & $2(5.5 \%)$ & $0(0 \%)$ \\
\hline \multicolumn{4}{|c|}{ Triglycerides (mg/dl) 10-12 years (Daniels and Greer 2008; McNeal et al. 2013) } \\
\hline Acceptable (50-90) & $4(50 \%)$ & $2(33.3 \%)$ & $3(60 \%)$ \\
\hline Borderline (91-129) & $3(37.5 \%)$ & $4(66.4 \%)$ & $1(20 \%)$ \\
\hline $\operatorname{High}(\geq 130)$ & $1(12.5 \%)$ & $0(0 \%)$ & $1(20 \%)$ \\
\hline \multicolumn{4}{|l|}{ Serum calcium (mg/dl) } \\
\hline Low 8.0-8.4 & $16(30.8 \%)$ & $2(4.4 \%)$ & $3(11.1 \%)$ \\
\hline Normal8.5-8.9 & $26(50 \%)$ & $2(4.4 \%)$ & $16(59.3 \%)$ \\
\hline Normal 9.0-9.4 & $7(13.5 \%)$ & $20(44.4 \%)$ & $8(29.6 \%)$ \\
\hline Normal 9.5-9.9 & $3(5.8 \%)$ & $13(28.9 \%)$ & $0(0 \%)$ \\
\hline Normal $>10$ & $0(0 \%)$ & $8(17.8 \%)$ & $0(0 \%)$ \\
\hline \multicolumn{4}{|l|}{ Serum magnesium (mg/dl) } \\
\hline Low $<1.5$ & $0(0 \%)$ & $0(0 \%)$ & $0(0 \%)$ \\
\hline
\end{tabular}


Table 6 (continued)

\begin{tabular}{cccc}
\hline & Enrolment $(\boldsymbol{n}=\mathbf{5 2})$ & $\mathbf{8}$ weeks $(\boldsymbol{n}=\mathbf{4 5})$ & $\mathbf{6}$ Months $(\boldsymbol{n}=\mathbf{2 7})$ \\
\hline Normal 1.5-1.7 & $32(61.5 \%)$ & $3(6.7 \%)$ & $1(3.7 \%)$ \\
Normal 1.8-2.2 & $20(38.5 \%)$ & $31(68.9 \%)$ & $22(81.5 \%)$ \\
Normal 2.3-2.6 & $0(0 \%)$ & $11(24.4 \%)$ & $4(14.8 \%)$ \\
\hline
\end{tabular}

On enrolment it was observed that $100 \%$ subjects had insufficient vitamin $C$ levels which was suggestive of reduced anti-oxidants in severely thin children and increased free radical injury and increased by-products of oxidative injury. Similar study carried out by Khare et al. revealed reduced number of anti-oxidants in severe acute malnutrition (2014).Vitamin $\mathrm{C}$ had a mean value of $0.46 \pm 0.05 \mathrm{mg} / \mathrm{l}$ on enrolment while at 8 weeks there was a sharp improvement with mean of $0.69 \pm 0.10 \mathrm{mg} / \mathrm{l}$ with a $t$ value of 13.8 and $p$ value of less than 0.001 which was statistically significant. At the end of 8 weeks, $91.1 \%$ subjects' vitamin $C$ levels improved to sufficient levels suggestive of reduction in oxidative stress. This can be attributed to micronutrient rich content of MNT which helps in improving anti-oxidant levels. Similar study carried out by Rahul Ghone et al. reported an improvement in anti-oxidants after supplementing with anti-oxidant therapy in severely malnourished children (2013). At end of 6 months, it was observed that vitamin $C$ levels dropped in $18.5 \%$ subjects most likely due to intercurrent illnesses suggestive of oxidative injury. Mean value of vitamin $C$ was $0.46 \pm 0.05 \mathrm{mg} / \mathrm{l}$ on enrolment with mean of $0.73 \pm 0.10 \mathrm{mg} / \mathrm{l}$ at end of 6 months with a t value of 11.6 and $p$ value of less than 0.001 which is statistically significant.

Mean cholesterol value on enrolment was $121.93 \pm 20.96 \mathrm{mg} / \mathrm{dl}$ with $92.3 \%$ subjects having less than desirable values of cholesterol. Similar study carried out by Verma et al. found decreased cholesterol levels in severely acute malnourished children between 6 and 59 months (2018). He also observed that malnutrition in early life leads to changes in lipid metabolism. After 8 weeks there was a sharp rise in cholesterol values to a mean of $148.29 \pm 16.96 \mathrm{mg} / \mathrm{dl}$ with a $\mathrm{t}$ value of 7.5 and $p$ value of less than 0.001 which is statistically significant. At 8 weeks it was observed that $44.4 \%$ of subject's cholesterol improved to desirable values while $8.9 \%$ subjects reached borderline values. This can be attributed to a dyslipidemia probably caused by high lipid content in MNT. At 6 months mean cholesterol was $150.96 \pm 14.47 \mathrm{mg} / \mathrm{dl}$ with $\mathrm{t}$ value of 1.9 and $p$ value of 0.07 which was statistically insignificant. It was also observed that number of subjects having borderline cholesterol levels fell sharply from 8.9 to $3.7 \%$ after discontinuation of MNT while 55\% subjects maintained cholesterol values in desirable ranges on follow-up at 6 months. The percentage of subjects having cholesterol in desirable range improved from 5.8 to $44.4 \%$ to $55.6 \%$ serially. Overall, there was mean improvement in cholesterol value from $121.93 \pm 20.96 \mathrm{mg} / \mathrm{l}$ (low) on enrolment to $150.96 \pm 14.47 \mathrm{mg} / \mathrm{dl}$ (desirable) at 6 months with $\mathrm{t}$ value of 7.1 and $p$ value of less than 0.001 which is statistically significant.

Mean value of HDL was $41.73 \pm 6.54 \mathrm{mg} / \mathrm{dl}$ (borderline) on enrolment, while at 8 weeks, it increased to $52.56 \pm 7.15 \mathrm{mg} / \mathrm{dl}$ (desirable) with a $\mathrm{t}$ value of 6.4 and $p$ value $<0.001$ which was statistically significant. Mean HDL at 6 months was $55.3 \pm 6.63 \mathrm{mg} / \mathrm{dl}$ with $\mathrm{t}$ value of 1.7 and $p$ value of 0.1 which was statistically insignificant. It should be noted that $69.2 \%$ of the subjects had borderline low/undesirable HDL levels even on enrolment. These findings are comparable with the study done by Verma et al. (2018) and Veiga et al. (2010). At 8 weeks there was a significant improvement in HDL to desirable levels $(51.1 \%)$ and only $17.8 \%$ of subjects had borderline low levels. $31.1 \%$ subjects were having borderline high HDL at 8 weeks. This is a good sign and can be due to lipid rich content of MNT. At end of 6 months HDL levels were maintained to desirable levels in $33.3 \%$ of subjects and there were no borderline high and elevated HDL levels. Overall, there was mean improvement in HDL from $41.73 \pm 6.54 \mathrm{mg} / \mathrm{dl}$ at enrolment to mean of $55.30 \pm 6.63 \mathrm{mg} / \mathrm{dl}$ at 6 months with $\mathrm{t}$ value of 9 and $p$ value of less than 0.001 which was statistically significant.

Mean value of LDL on enrolment was $63.16 \pm 16.13 \mathrm{mg} /$ $\mathrm{dl}$, while mean increased to $75.36 \pm 11.88 \mathrm{mg} / \mathrm{dl}$ at 8 weeks with $t$ value of 4.9 and p value of less than 0.001 which was statistically significant. $5.8 \%$ subjects had acceptable LDL values on enrolment which increased to $24.4 \%$ at end of 8 weeks. At 6 months LDL values continued to rise to $78.56 \pm 10.75 \mathrm{mg} / \mathrm{dl}$ with a $\mathrm{t}$ value of 1.9 and $p$ value of 0.06 which was statistically not significant. LDL levels were maintained to acceptable in $22.2 \%$ subjects at the end of 6 months. Overall we observed that the mean value of LDL was $63.16 \pm 16.13 \mathrm{mg} / \mathrm{dl}$ on enrolment which increased to $78.56 \pm 10.75 \mathrm{mg} / \mathrm{dl},(p<0.001)$. None of the children at 8 weeks and 6 months reached borderline high values during the study.

Mean triglyceride (5-9 years) was $72.23 \pm 18.04 \mathrm{mg} /$ $\mathrm{dl}$ on enrolment which increased to $118.26 \pm 27.37 \mathrm{mg} /$ 
$\mathrm{dl}$ at 8 weeks, $(p<0.001) .50 \%$ of subjects on enrolment had acceptable values on enrolment. Borderline high levels of triglycerides were detected in $38.6 \%$ of subjects even at enrolment. Study carried out by Gabriela Viega et al. reported a similar finding with hypertriglyceridemia and low HDL values (2010).It is assumed, therefore, that the high frequency of dyslipidemia observed in the present study could be a consequence of the adaptation to longstanding malnutrition, although there are currently no studies to support this assumption. At 8 weeks, 20.1\% pts reached high levels of triglycerides on MNT. This can be attributed to lipid rich values of MNT. At 6 months, triglyceride levels continued to rise to $120.91 \pm 14.89 \mathrm{mg} /$ $\mathrm{dl}$ with a $\mathrm{t}$ value of 0.92 and $p$ value of 0.36 which is statistically insignificant. At 6 months it was observed that there were no high and borderline high values of triglycerides after discontinuation of MNT. These findings are in accordance with the previous studies (Veiga et al. 2010; Alves et al. 2014) suggesting that even though elevated triglyceride levels were observed while on MNT, it does not remain high after discontinuation of MNT. This is a very good sign.

Mean triglyceride values (10-12 years) on enrolment were $93.33 \pm 25.46 \mathrm{mg} / \mathrm{dl}$ and at 8 weeks it was $115.83 \pm 21.35 \mathrm{mg} / \mathrm{dl}$ with $\mathrm{t}$ value of 1.4 and $\mathrm{p}$ value was 0.23 which was statistically not significant. Here also similarly, we also observed that between 10 and 12 years, 50\% of subjects had acceptable values, while $37.5 \%$ subjects had borderline levels on enrolment. After 8 weeks, $66.4 \%$ subjects had borderline high values. After 6 months borderline high values reduced to $20 \%$ in subjects. Further studies are required on a larger scale to draw a definite conclusion but the reduced trend at 6 months is a good sign.

There was a mean increase in serum calcium from $8.60 \pm 0.39 \mathrm{mg} / \mathrm{dl}$ at enrolment to $9.29 \pm 0.27 \mathrm{mg} / \mathrm{dl}$ at 6 months with $\mathrm{t}$ value of 7.4 and $p$ value $<0.001$ which was significant. There was an overall increase in serum magnesium from $1.66 \pm 0.24 \mathrm{mg} / \mathrm{dl}$ to $2.04 \pm 0.18 \mathrm{mg} / \mathrm{dl}$ ( $p$ value $<0.001)$ which was also statistically significant. Thus, we can infer that MNT improves the micronutrient status of severely thin subjects.

\section{Conclusions}

Medical Nutrition Therapy or indigenously prepared Ready-to-Use Therapeutic Food is effective in treating acute malnutrition in Severe Thin children, and it should be promoted as the treatment of choice for children in age group of 5-12 years. It definitely helps in reducing the oxidative stress. It promotes recovery at micronutrient level. It also promotes improvement in HDL cholesterol. It causes transient dyslipidemia.

Limitations of the study include:
1. Sample size is too less to study variations in MNT at 6 months.

2. Follow-up: $14 \%$ subjects did not follow-up at 8 weeks, while $48 \%$ subjects were lost to follow-up at 6 months.

\section{Abbreviations}

SAM: Severe acute malnutrition; BMI: Body Mass Index; MNT: Medical nutrition therapy; ST: Severely thin; RUTF: Ready-to-use Therapeutic food; MDA: Malondialdehyde; GPO: Glycerol-3-phosphate-oxidase; HDL: High-density lipoprotein; LDL: Low-density lipoprotein.

\section{Acknowledgements}

Dean LTMMC \&GH (Lokmanya Tilak Municipal Medical College \& General Hospital) \& Dr. Radha G. Ghildiyal Head of the Department of Pediatrics (Lokmanya Tilak Municipal Medical College \& General Hospital).

\section{Authors' contributions}

DrW contributed to conception, design, original draft, interpretation of data, revision of draft. Dr BD helped in design, acquisition of data. Dr VDS contributed to conception, design, final revision of draft, interpretation of data. Dr PK helped in design, conception. Dr AJ contributed to conception, design, revision of draft, interpretation of data. Dr MJ contributed to acquisition of data. BR helped in acquisition of data, interpretation of data. LF contributed to acquisition of data and interpretation of data. All authors read and approved the final manuscript.

\section{Funding}

Tata Motors Pvt Ltd (India).

Availability of data and materials

The datasets used and/or analysed during the current study are available from the corresponding author on reasonable request.

\section{Declarations}

\section{Ethics approval and consent to participate}

Ethics approval has been given by Staff \& Research Society of Lokmanya Tilak Municipal Medical College and General Hospital Ref no D0201743 dated 1 March 2017. Written informed consent for participation has been taken.

Consent for publication

Written informed consent for publication has been taken.

\section{Competing interests}

The authors declare no competing interests.

\section{Author details}

${ }^{1}$ Department of Paediatrics, Lokmanya Tilak Municipal Medical College and General Hospital, Mumbai, India. ${ }^{2}$ Department of Biochemistry, Lokmanya Tilak Municipal Medical College and General Hospital, Mumbai, India. ${ }^{3}$ Department of Paediatrics, TNMC \& BYL Nair Hospital, Mumbai, Maharashtra 400008, India. ${ }^{4}$ Division of Paediatric Gastroenterology, Hepatology and Nutrition-in Charge, Department of Paediatrics, Lokmanya Tilak Municipal Medical College and General Hospital, Mumbai, India. ${ }^{5}$ Clinical Nutrition and Dietetics, Lokmanya Tilak Municipal Medical College and General Hospital, Mumbai, India.

Received: 26 August 2021 Accepted: 20 February 2022

Published online: 03 March 2022 


\section{References}

Alves J, Britto R, Ferreira H, Sawaya A, Florêncio T (2014) Evolution of the biochemical profile of children treated or undergoing treatment for moderate or severe stunting: consequences of metabolic programming? J Pediatria 90:356-362. https://doi.org/10.1016/j.jped.2013.12.007

Catal F et al (2007) Oxidant and antioxidant status of turkish marasmic children: a single center study. J Trace Elem Med Biol 21(2):108-112. https:// doi.org/10.1016/j.jtemb.2007.01.003

Daniels SR, Greer FR (2008) The Committee on Nutrition: lipid screening and cardiovascular health in childhood. Pediatrics 122:198-208. https://doi. org/10.1542/peds.2008-1349

Emery PW (2005) Metabolic changes in malnutrition. Eye 19(10):1029-1034. https://doi.org/10.1038/sj.eye.6701959

Ghone RA, Suryakar AN, Kulhalli PM, Bhagat SS, Padalkar RK, Karnik AC et al (2013) A study of oxidative stress biomarkers and effect of oral antioxidant supplementation in severe acutemalnutrition. J Clin Diagn Res 7:2146-2148. https://doi.org/10.7860/JCDR/2013/6019.3454

Jadhav A, Dias B, Shah N, Fernandes L, Fernandes S, Surve A et al (2016) A randomized controlled facility based trial to assess the impact of indigenously prepared ready to use therapeutic food (RUTF) for children with severe acute malnutrition in India. Pediatric Oncall. https://doi.org/10. 7199/ped.oncall.2016.61

Jadhav AR, Karnik P, Fernandes L, Fernandes S, Shah N, Manglani M (2019) Indigenously prepared ready-to-use therapeutic food (RUTF) in children with severe acute malnutrition. Indian Pediatr 56:287-293

Jain A, Varma M, Agrawal BK, Jadhav AA (2008) Serum zinc and malondialdehyde concentrations and their relation to total antioxidant capacity in protein energy malnutrition. J Nutr Sci Vitaminol 54:392-395. https://doi. org/10.3177/jnsv.54.392

Khare M, Mohanty C, Das BK, Jyoti A, Mukhopadhyay B, Mishra SP (2014) Free radicals and antioxidant status in protein energy malnutrition. Int J Pediatr 2014:254396. https://doi.org/10.1155/2014/254396

Lenters L et al. (2016) Management of severe and moderate acute malnutrition in children. In: Black RE et al (ed) Reproductive, maternal, newborn, and child health: disease control priorities, 3edn, vol 2, The International Bank for Reconstruction and Development/The World Bank, 2016. PubMed. http://www.ncbi.nlm.nih.gov/books/NBK361900/

McNeal CJ, Underland L, Wilson DP, Blackett PR (2013) Pediatric lipid screening. Clin Lipidol 8:425-436. https://doi.org/10.2217/clp.13.42

Sawant VD, Viswanathan V, Jadhav A, Jadhav M, Krishna S (2021) Assessment of clinical outcome in children with severe thinness on medical nutrition therapy at 8 weeks and 6 months. Curr Res Nutr Food Sci 9:2

Sawaya AL et al. (2009) Malnutrition, long-term health and the effect of nutritional recovery. In: Kalhan SC et al (2009) Nestlé nutrition institute workshop series: pediatric program, vol 63, KARGER, pp. 95-108. https:// doi.org/10.1159/000209975

Veiga GRS, Ferreira HS, Sawaya AL, Calado J, Florêncio TMMT (2010) Dyslipidaemia and undernutrition in children from impoverished areas of Maceió, state of Alagoas, Brazil. IJERPH 7:4139-4151. https://doi.org/10.3390/ijerp h7124139

Verma GK, Yadav YS, Yadav RK, Sharma IK, Bharat K, Yadav KK (2018) Study of lipid profile levels in malnourished and healthy children: a case control study. Pediatric Rev Int J Pediatric Res 5(4):156-161

\section{Publisher's Note}

Springer Nature remains neutral with regard to jurisdictional claims in published maps and institutional affiliations.

\section{Submit your manuscript to a SpringerOpen ${ }^{\circ}$ journal and benefit from:}

- Convenient online submission

- Rigorous peer review

- Open access: articles freely available online

- High visibility within the field

- Retaining the copyright to your article

Submit your next manuscript at $\boldsymbol{\nabla}$ springeropen.com 